\title{
A new species of Cervellus Szépligeti (Hymenoptera, Braconidae, Braconinae) with biological notes
}

\author{
Angélica Maria Penteado-Dias ${ }^{1}$, Marcos Antonio Barbosa Moreira² \& Paulo Henrique Gorgatti Zarbin ${ }^{3}$
}

${ }^{1}$ Universidade Federal de São Carlos, Departamento de Ecologia e Biologia Evolutiva. Caixa Postal 676, 13565-905 São Carlos-SP, Brasil.
angelica @ power.ufscar.br
${ }^{2}$ Universidade Federal do Paraná, Departamento de Zoologia, Caixa Postal 19020, 81531-980 Curitiba-PR, Brasil.
${ }^{3}$ Universidade Federal do Paraná, Departamento de Química, Caixa Postal 19081, 81531-990 Curitiba-PR, Brasil. pzarbin@quimica.ufpr.br

\begin{abstract}
A new species of Cervellus Szépligeti (Hymenoptera, Braconidae, Braconinae) with biological notes. A new Cervellus species is described from Brazil. The male to this genus is described for the first time as well its cocoon is illustrated. The specimens parasitize the papaya borer weevil Pseudopiazurus obesus (Boheman, 1838) (Coleoptera, Curculionidae) associated with Carica papaya Linnaeus, 1753 (Caricaceae) at Rio Grande do Norte and Bahia Brazilian States.
\end{abstract}

KEYWORDS. Biological control; Carica papaya; parasitoids; taxonomy.

RESUMO. Uma nova espécie de Cervellus Szépligeti (Hymenoptera, Braconidae, Braconinae), com notas biológicas. O trabalho apresenta a descrição de uma nova espécie brasileira de Cervellus. O macho é descrito pela primeira vez; o casulo é ilustrado. Os espécimes parasitam larvas de Pseudopiazurus obesus (Boheman, 1838) (Coleoptera, Curculionidae) sobre Carica papaya Linnaeus, 1753 (Caricaceae) nos estados brasileiros do Rio Grande do Norte e Bahia.

PALAVRAS-CHAVE. Carica papaya; controle biológico; parasitóides; taxonomia.

The Braconinae is a large subfamily of moderately small to large wasps with more than 2000 described species worldwide (Shaw \& Huddleston 1991). Few studies have been made on the New World fauna since the first two decades of the last century. The biologies of many of the Neotropical genera are still unknown. The Braconinae have a cosmopolitan distribution, with the greatest generic and probably specific diversity being in the Old World tropical regions. The Nearctic fauna is similar in its generic composition to that of the Palearctic, but in the Neotropics, most genera are endemic.

The genus Cervellus has few species infrequently collected and has distribution on Trinidad and South America, but not recorded from Chile. One species has been reared from a coleopteran larva (Quicke 1989); Fahringer (1930) presents a key to its species; Yu et al. 2005 present five valid species.

We present here a new Cervellus species, discussing its diagnostic characters and presenting biological information. For the recognition of the subfamily Braconinae and the genus Cervellus, see Quicke, in Wharton et al. (1997). The new species here described was compared with other species presented in Fahringer (1930). The type material is deposited at the Departamento de Ecologia e Biologia Evolutiva da Universidade Federal de São Carlos, SP, Brazil (DCBU).

Cervellus piranga $\mathbf{s p . ~ n o v . ~ P e n t e a d o - D i a s ~}$

(Figs 5-19)

Material. - Holotype, 우 (DCBU), "[Brazil] RN, Touros, 15.V.2002, M.A. B. Moreira col." Paratypes, $30^{\pi} \sigma^{\pi}, 2$ 우 우 (DCBU), same label data; $30^{x} 0^{x}, 2$ 우 (DCBU) "[Brazil] BA, Laje, 18-29.X.2004, M. A . Moreira col."

Holotype, ㅇ, length of body $10.0 \mathrm{~mm}$, fore wing $11.0 \mathrm{~mm}$.

Head. Antenna with 70 segments and as long as fore wing, first flagellomere with thorn-like pre-apical projection (Figs 8, 9). Face with distinctive and massive protuberance with concave dorsal face and with concave frontal aspect (Fig. 12); face and clypeus smooth, near the internal margin of eyes with long hairs and rugose; occipital carina completely absent; vertex smooth; height of eye 4.5 the malar space (Fig. 11). Ocelli in a elevated area; ocellus-ocular distance near 4.0x the diameter of lateral ocellum. Base of mandible with long hairs .

Mesosoma. Length of mesosoma 1.5 times its height (Figs $15,16)$; side of pronotum nearly completely smooth; all mesosoma smooth and shiny; propleuron hirsute with pair of boss-like, medially-orientated projections antero-medially (Fig 13); mesopleuron and metapleuron hirsute; mesosternum with lines of long hairs; sternaulus not impressed; notauli present; scutellar sulcus shallow with some carinae (Fig. 15). Propodeum shiny and smooth with long hairs (Fig. 16).

Wings.- Fore wing (Fig. 6) : r 1/5 long as 3-SR; pterostigma elliptical; cu-a slightly post-furcal; m-cu antefurcal, slightly postfurcal. Hind wing : $1 \mathrm{M}: \mathrm{M}+\mathrm{CU}=6: 1$.

Legs.- Length of femur, tibia and basitarsus of hind leg 4.0, 8.0 and 4.0 times their width, respectively; hind femur and tibia with hairs; tarsal claws simple.

Metasoma. Length of first tergite 1.4 times its apical width (Fig.17) with distinct dorso-lateral carinae, its surface largely 

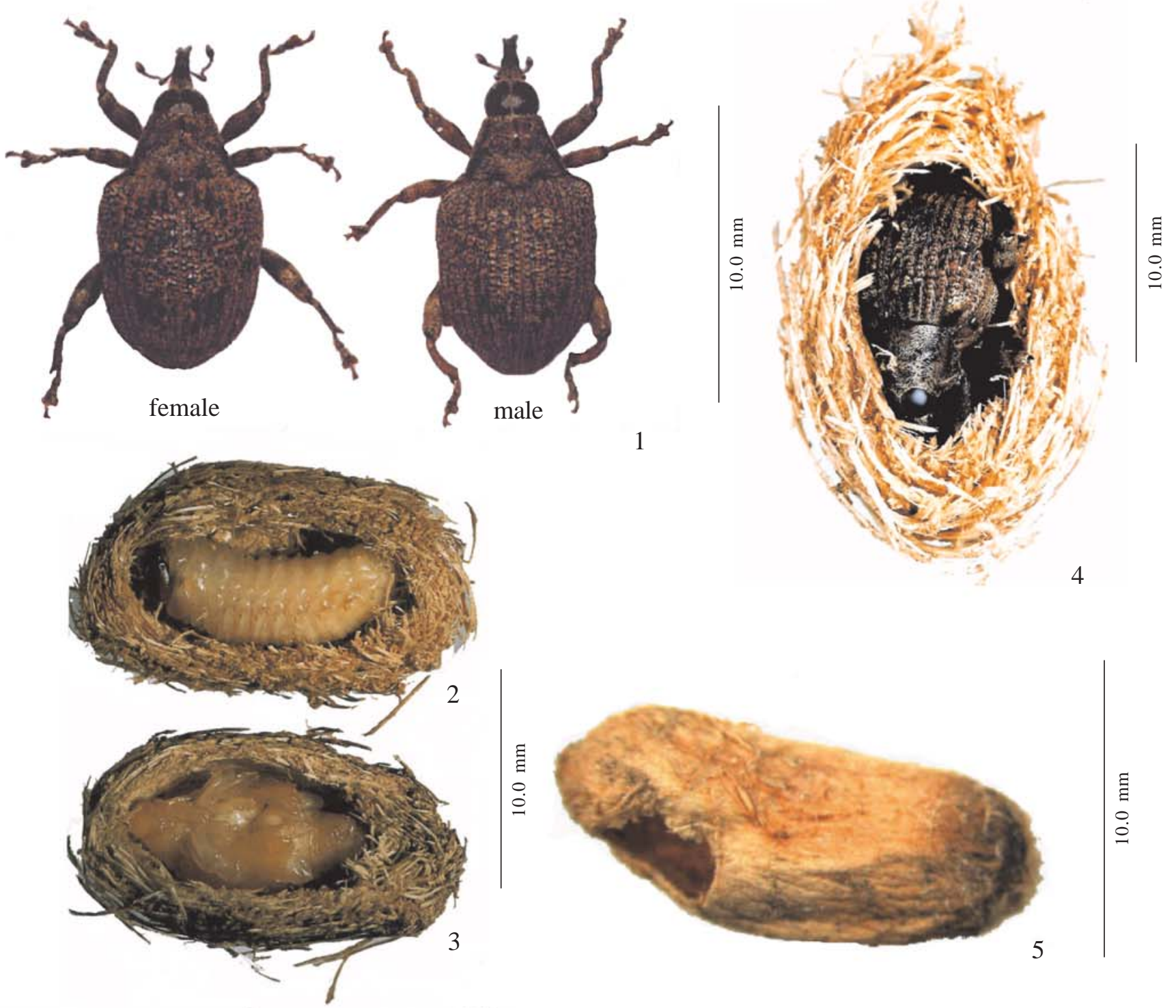

1
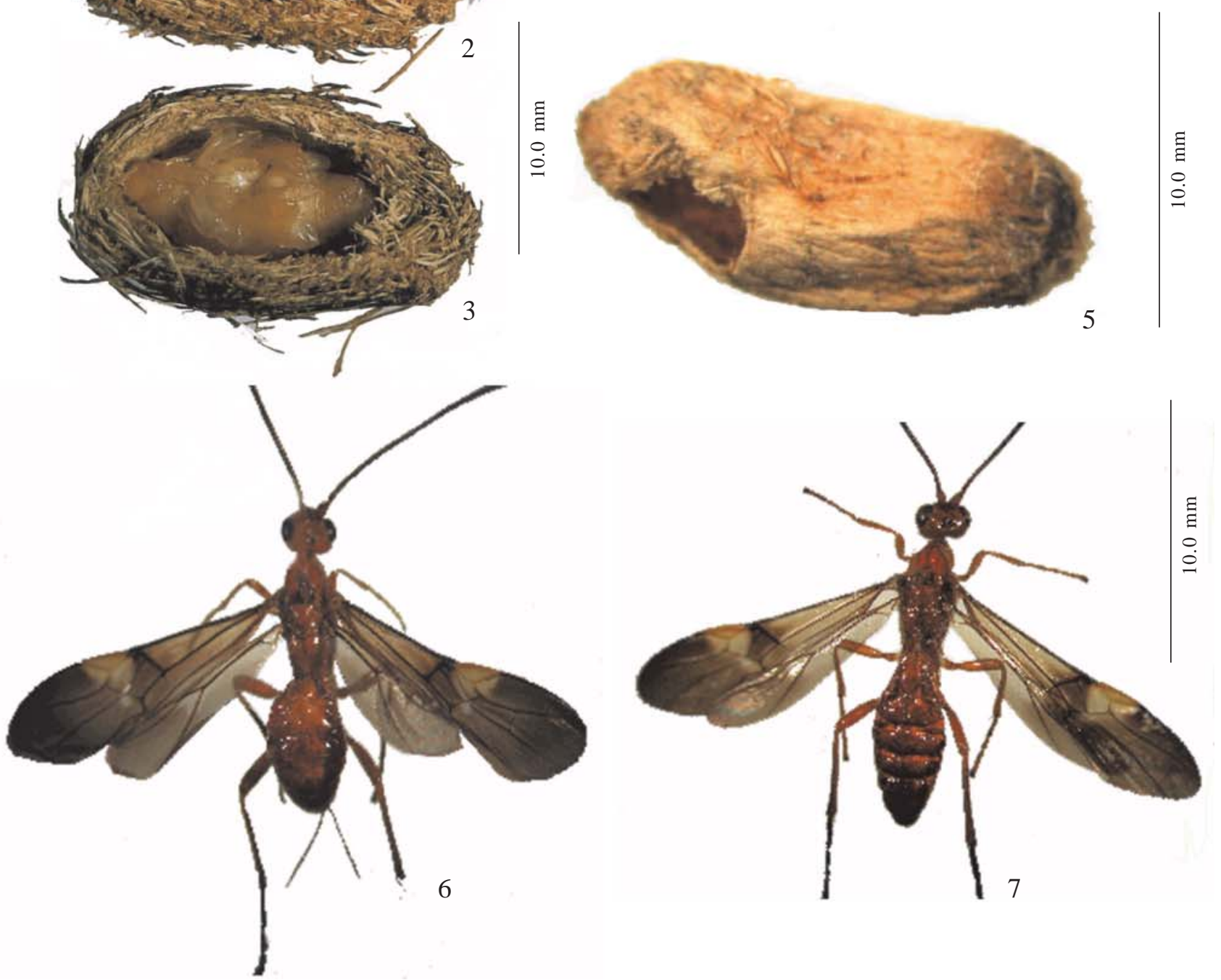

Figs. 1-7. 1-4, Pseudopiazurus obesus (Boheman, 1838). 1, female and male; 2, larva in chamber; 3, pupa in chamber; 4, adult in chamber. 5-7, Cervellus piranga sp. nov. 5, coccon; 6 , habitus, female; 7, habitus, male. 

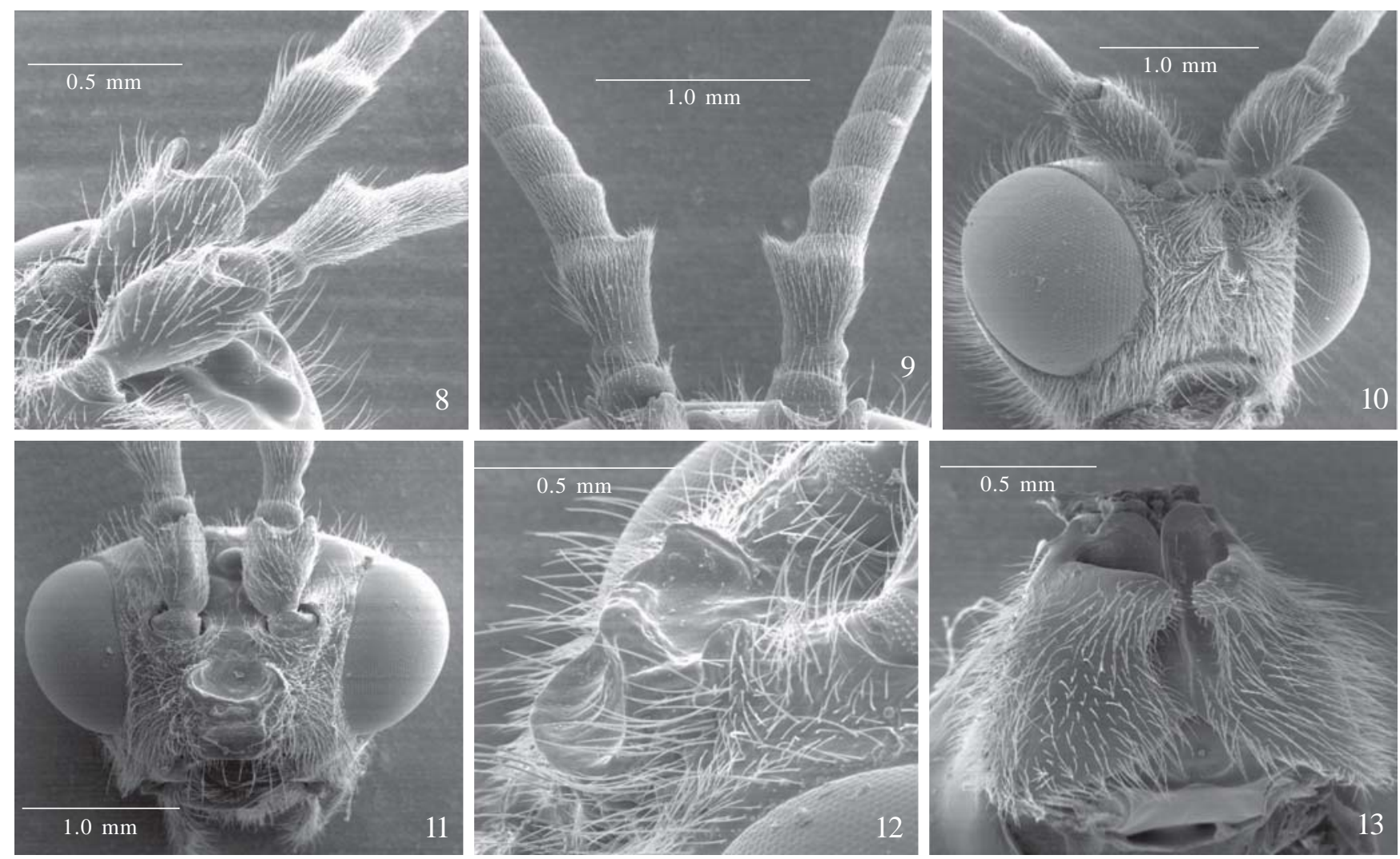

Figs. 8-13. Cervellus piranga sp. nov. 8, 9, first antennomeres, female; 10, face, male; 11, head, frontal, female; 12, facial massive protuberance, female; 13, propleurum, female.
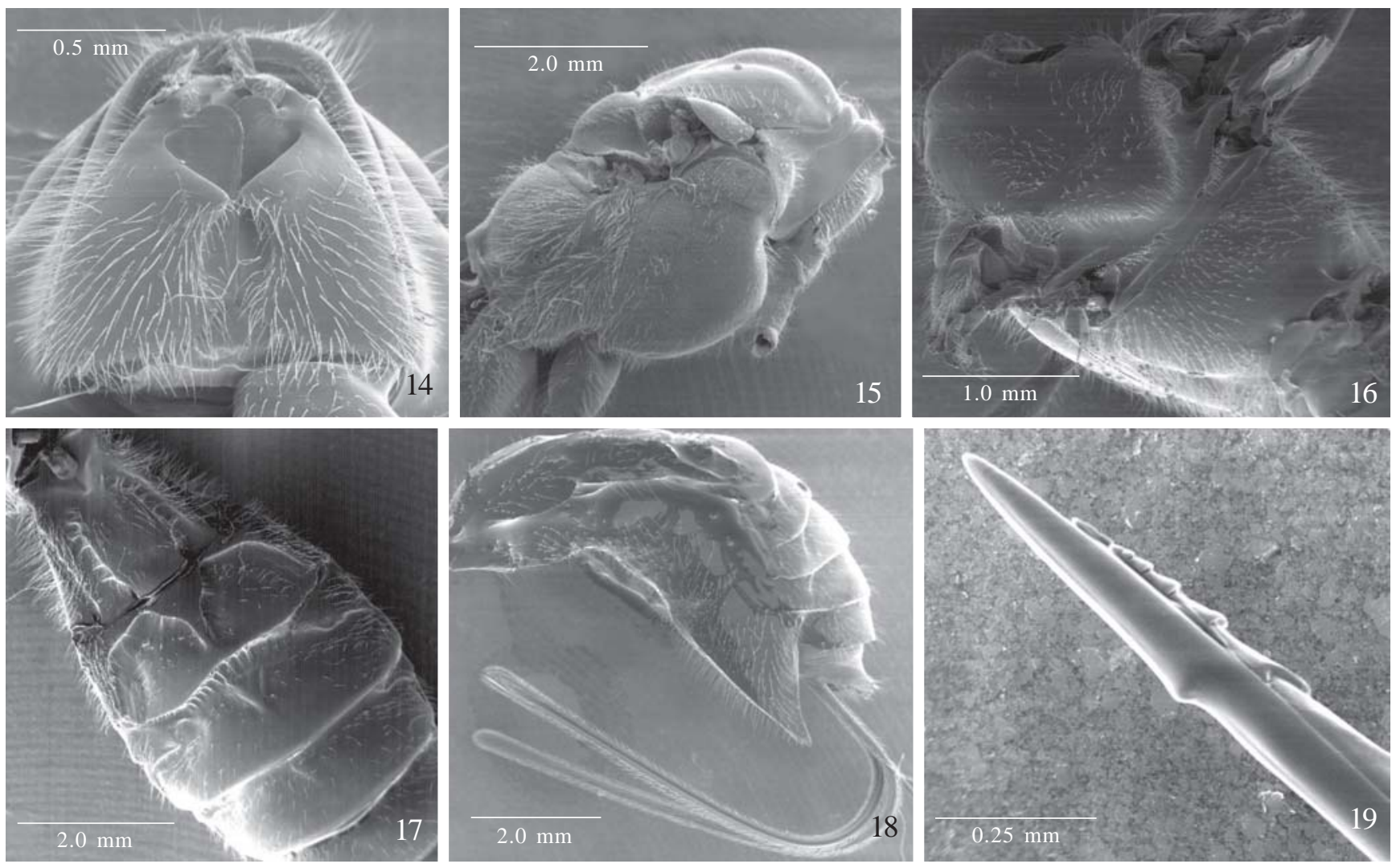

Figs. 14-19. Cervellus piranga sp. nov. 14, propleurum male; 15, 16, mesosoma, female; 17, 18, metasoma, female; 19, apex of ovipositor. 
smooth. Posterior margin of metasomal tergum 2 sculptured . Hypopygium pointed and as long as the apex of the metasoma; length of ovipositor sheath 0.8 times the fore wing (Fig. 18). Apex of ovipositor with subapical teeth (Fig. 19).

Color. Reddish; all flagellomeres, except the first and apical metasoma blackish; fore wing (Fig. 6) yellowish hyaline with two fumated bands, stigma yellow; hind wing with apical half fumated; tarsal claws blackish.

Male (Fig. 7): similar to female, but without the protuberance on face and the thorn-like pre-apical projection on the first flagellomere; height of eye 6.0 the malar space (Fig 10); propleuron as the female (Fig. 14).

Biology. The specimens were reared from the papaya borer weevil Pseudopiazurus obesus (Figs. 1-4) associated with Carica papaya in Brazil. For detailed descriptions of the immature stages of the Coleoptera see Souza et al. (2004). Other biological information of that species is in Bondar (1948). The parasitoid cocoon is illustrated as the Fig. 5.

Comments: the vertex of head and propleuron can be blackish in some specimens. This is the first citation to male of Cervellus species what can show the main character to identify this genus, the propleuron with pair of boss-like, mediallyorientated projections antero-medially (Figs 13,14). This is the only character common to female and male specimens. The antennae and the face of the male are simple. Fahringer (1930) has cited only females of Cervellus nodicornis (Brullé, 1846) and its variety C. n. bruesi Fahringer, 1930, from Brazil, C. antennatus (Brullé, 1846) and C. a . ruficornis Fahringer, 1930 from Brazil, C. denticornis (Szépligeti 1904), from Peru and C. ramicornis (Brullé,1846) from Guyana. C. denticornis like $C$. piranga sp. nov. has the first flagellomere with a thornlike pre-apical projection, but it has the body mostly black and the stigma of wing is not all yellow. C. piranga sp. nov. is the only species with all body, including the legs, with red color and fore wing with all stigma yellow.

Etymology: The name to species refers to reddish general color of the body. The word piranga means red in tupy language.

Acknowledgments. We are grateful to the Conselho Nacional de Desenvolvimento Científico e Tecnológico, Brasil (CNPq) and Fundação de Amparo à Pesquisa do Estado de São Paulo (FAPESP) for the financial support.

\section{REFERENCES}

Bondar, G. 1948, Broca do mamoeiro (Pseudopiazururs papayanus Mshl.) Boletim do campo 23: 1-2.

Fahringer, J. 1930 . Über einige südamerikanische Braconidengattungen. Wiener entomologische Zeitung 47: 19-31.

Quicke, D. L. J. 1989. Further new host records for genera and species of Braconinae (Hym., Braconidae). Entomologist's Monthly Magazine 125: 199-205.

Quicke, D. L. J. 1997. Subfamily Braconinae, p. 149-174. In: R. A . Wharton; P. M. Marsh \& M. J. Sharkey (eds.). Manual of the New World genera of the family Braconidae (Hymenoptera). Special Publication of The International Society of Hymenopterists. Number 1, 439 p.

Shaw, M. R. \& T. Huddleston. 1991. Classification and biology of braconid wasps (Hymenoptera, Braconidae). Handbooks for the Identification of British Insects 7: 1-126.

Souza, W. O.; G. H. Rosado-Neto; M. A .B. Moreira \& P. H. G. Zarbin 2004. Description of the larva and pupa of the papaya borer weevil Pseudopiazurus papayanus (Marshall) ( Coleoptera, Curculionidae, Piazurini).Revista Brasileira de Entomologia 48: 331-334.

Yu, D. S.; K. van Achterberg \& K. Horstmann 2005. World Ichneumonoidea. CD Rom Taxapad. 